\title{
Macromolecular Antiproliferative Agents Featuring Dicarboxylato-Chelated Platinum
}

\author{
L. L. Komane ${ }^{1}$, E. H. Mukaya ${ }^{1}$, E. W. Neuse ${ }^{1}$ and C. E. J. van Rensburg ${ }^{2}$ \\ (1) School of Chemistry, University of the Witwatersrand, WITS, 2050, South Africa \\ (2) Department of Pharmacology, University of Pretoria, P. O. Box 2034, Pretoria, \\ 0001, South Africa
}

E.W. Neuse
Email: NEUSE@aurum.wits.ac.za

\begin{abstract}
Cancerous diseases, together with cardiac afflictions, account for the predominant causes of death among the adult population of the Western world. The classical platinum drugs, with cisplatin as their parent, have established themselves for years as leading components in the oncologist's arsenal of antitumor agents. As with most other antineoplastic drugs, however, incisive pharmacological deficiencies, notably excessive systemic toxicity and induction of drug resistance, have severely curtailed their overall efficaciousness. With the objective of overcoming these counterproductive deficiencies, the technique of polymer-drug conjugation, representing an advanced modality of drug delivery, has been developed in recent years to high standards worldwide. In a drug conjugate, water-soluble macromolecular carrier constructs designed in compliance with stringent pharmacological specifications are covalently, yet bioreversibly, interconnected with the bioactive agent. As a macromolecule following a pharmacokinetic pathway different from that of non-polymeric compounds, the conjugate acts as a pro-drug favorably transporting the agent through the various body compartments to, and into, the target cell, where the agent is enzymatically or hydrolytically separated from the carrier for its biological action. In the authors' laboratories the conjugation strategy has been adopted as the primary tool for drug efficacy enhancement. The present paper describes a special type of platinum complex carrier-bound via dicarboxymetal chelation, synthesized from carboxyl-functionalized polyamide-type carriers by platination with trans-1,2-diaminocyclohexanediaquaplatinum(II) dinitrate. In a series of in vitro tests antiproliferative activities have been determined against several human cancer cell lines. Whereas no improvements are observed in tests against a colorectal cancer, outstanding findings of the screening program include a 10- to 100-fold increase in cell-killing performance of the conjugates relative to the (non-polymeric) cisplatin standard against the HeLa adenocarcinoma, and distinctly reduced resistance factors (again, relative to cisplatin) in tests against the A2780 and A2780-cis pair of ovarian cell lines. These findings augur well for future developments of this class of platinum drugs.
\end{abstract}


This article is dedicated to Professor Astruc.

\section{Introduction: Square-Planar Platinum Compounds in Oncology}

The family of platinum-containing medicinal agents used for the chemotherapy of malignancies ranks among the most potent types of anticancer drug in present use. For many years since early reports [1], the parent drug, cisplatin, cis-diamminedichloroplatinum(II) (Fig. 1), has been in the forefront of metalorganic drug research, and countless relatives containing the square-planar structural skeleton of the parent compound have been developed [2-4].
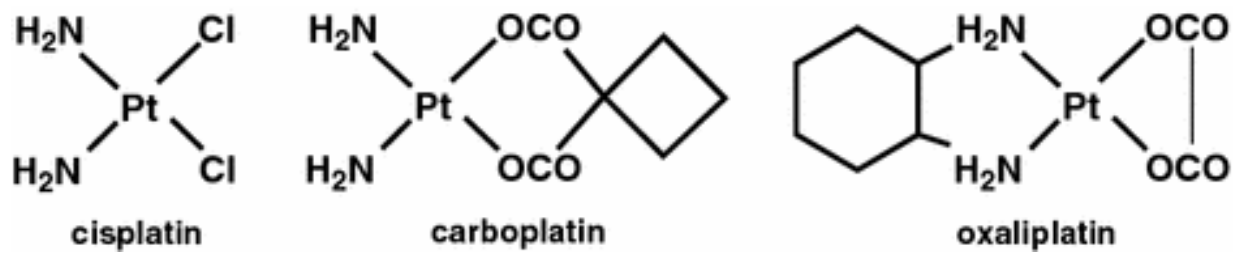

Fig. 1 Structures of leading platinum drugs

In the structural pattern of cisplatin, two firmly bound $\mathrm{NH}_{3}$ ligands in cisoid geometry coordinate to the metal, and two chloro ligands complete the coordination pattern, these two chloro ligands being of the "leaving group" type and, hence, readily displaceable, e.g. by the aqua ligand. The two leaving group positions in cisplatin thus serve as the sites of substitution reactions involved in the drug's post-administration pharmacokinetic pathway, which ultimately leads to crosslinking with the affected cell's nuclear DNA and irreversible lesions in the double-helix with consequent cell death.

While highly potent against many cancers, cisplatin like other anticancer drugs suffers from virtually all of the clinical limitations observed with metal-free antitumor agents in current clinical use, most notably toxic side effects and a propensity for eliciting drug resistance in the cancerous cell. Acute toxicity, generally dose-limiting, leads to a disproportionately small difference between the toxic and the minimum effective serum concentration levels. As a consequence, it will generally be necessary to discontinue drug administration long before satisfactory remission-free cure rates are attained. In addition, drug action is non-selective, normal and transformed cells being equally affected. Other undesirable characteristics include poor water solubility, with detrimental effects on distribution in the central circulation system, and short residence times in the latter, paired with rapid depletion through urinary excretion and consequent unpredictable variation of drug concentrations. The electrophilic nature of cisplatin in its aquated form (cis-diamminediaquaplatinum(II) dication), as partially present when dissolved in central circulation, results in high affinity to amino acids and proteins. Rapid protein binding removes some $90 \%$ of administered cisplatin irreversibly from serum and cytosolic space with resultant reduction in bioavailability. The drug resistance problem, which usually materializes upon repeated drug administration and may have even more formidable 
biomedical consequences, is associated with cellular reaction to the intrusion of a foreign body into intracellular space. The affected cell's resistance to the drug may be intrinsic, being present even prior to chemotherapy. This type of resistance to cisplatin is exhibited, inter alia, by human colorectal and breast carcinomas and melanoma, rendering most of these cancer lines refractory to the drug. In contrast, acquired resistance is typically encountered upon repeated chemotherapy and results from progressive increase in the fraction of cancer cell mutants insensitive to the drug as the sensitive cell population is eliminated in the treatment. Acquired resistance is thought to be multifactorial, the principal factor being decreased drug accumulation in the resistant cells. In contrast to the multi-drug resistance phenomenon associated with certain other antitumor agents, in which increased P-glycoprotein-mediated drug efflux causes the intracellular deficiency of the agent, the reduced accumulation of cisplatin (and presumably of the second-generation platinum complexes as well) appears to be largely the result of diminished drug influx, possibly associated with defect membrane transport. Other factors include accelerated DNA repair, as well as enhanced detoxification by increased intracellular levels of glutathione and glutathione transferase.

The pharmacological deficiencies of cisplatin enumerated in the foregoing have prompted development work on a massive scale in an effort to improve the drug's overall performance spectrum. The second-generation platinum drugs, with carboplatin (cisdiammine-1,1-cyclobutanedicarboxylatoplatinum(II); Fig. 1) clearly the forerunner, were the first tenable outcomings in those efforts. In carboplatin and related structures, such as oxaliplatin (Fig. 1) the two amine ligands again are tightly bound, and the two carboxylato ligands function as the leaving groups. Salient topics of platinum drug research, including second-generation compounds, have been reviewed, both very early in the game [5-11] and in more recent years [12-20].

Although some significant improvements in the pharmacological performance spectrum have resulted from the introduction of the second-generation platinum drugs, serious therapeutic shortcomings remain. As the search for ever more efficacious drug performance continues, pharmaceutical researchers worldwide are increasingly turning their attention to the technology of polymer-drug conjugation as a powerful tool to achieve enhanced therapeutic effectiveness. The following section will provide a brief, general background to the drug-conjugation concept, before we return to the platinum drugs and find out just how we might improve their therapeutic potential with the aid of this rather non-conventional, yet highly promising strategy.

\section{Polymer-Drug Conjugation: A Background Discussion}

The drug conjugation concept, based on a model in which a medicinal agent is temporarily bound to a polymeric carrier molecule, teaches the utilization of macromolecular compounds as pivotal "partners-in-healing" for the enhancement of therapeutic drug effectiveness [21]. Briefly, taking advantage of the more favorable 
pharmacokinetics of macromolecules relative to nonpolymeric compounds, a nonpolymeric biologically active agent is bioreversibly attached, conjugated, to a watersoluble polymeric carrier synthesized in strict compliance with biomedical specifications. The resultant, intravenously administered conjugate, in which the carrier component accepts the role of a transport vehicle, acts as a pro-drug. Being designed so as to travel essentially intact from central circulation through the various body compartments to, and into, the affected target (which, in cancer chemotherapy, is the neoplastic cell), it will release the bioactive agent at that site by enzymatic (or simply, at the endosomal $\mathrm{pH}$ of 5 , by hydrolytic) mechanisms for ultimate biological action. This sequence of events, schematically depicted in the flow chart of Scheme 1, is facilitated by a number of beneficial factors. Thus, macromolecules, in contrast to non-polymeric materials, utilize the enhanced permeation and retention (EPR) effect [22], by which they tend to accumulate in mammalian tumors as a result of tumor vascular leakage and reduced lymphatic clearance. This effect leads to enhanced bioavailability in the target tissue. The conjugate's water solubility will permit rapid distribution in the central circulation pool, thus avoiding capture by the reticuloepithelial system, a fate commonly suffered by undissolved particulate matter entering the body's fluid compartments. The conjugate will be temporarily protected against attack by other, aggressive serum constituents, thus prolonging serum residence life time. There will be drastically diminished toxic side effects because of the transitory nature of the polymer-anchored state, preventing premature drug accumulation in unaffected tissue and furthering drug availability in the affected cells. The last-named effect will additionally be facilitated by the aforementioned EPR effect, paired with the action of polymer-attached homing devices possessing affinity to the target tissue. Cell entry will be facilitated through the action of an adsorptive pinocytotic mechanism instead of the poorly efficient passive diffusion as generally utilized by non-polymeric compounds. This benefit will prove its value particularly in the fight against resistance, as it compensates for the accelerated, Pglycoprotein-mediated drug efflux suffered by the resistant cell. The net consequence of the discussed features is a significantly widened therapeutic window, grossly increased drug availability paired with reduced or eliminated detrimental side effects, and overall enhanced therapeutic effectiveness. Not surprisingly in view of these pharmacological gains provided by the drug conjugation modality, there has been extensive development work worldwide utilizing this modality, and the literature abounds with reports of successful polymer-drug binding, most of these focusing on the conjugation of such "classical" anticancer agents as methotrexate, daunomycin, neocarcinostatin, 5fluorouracil, or ARA-C. Many such carrier-bound agents have entered clinical trials with promising results, which has opened a wide field for further challenging exploration. The topic has been amply reviewed over the past two decades [22-33]. 


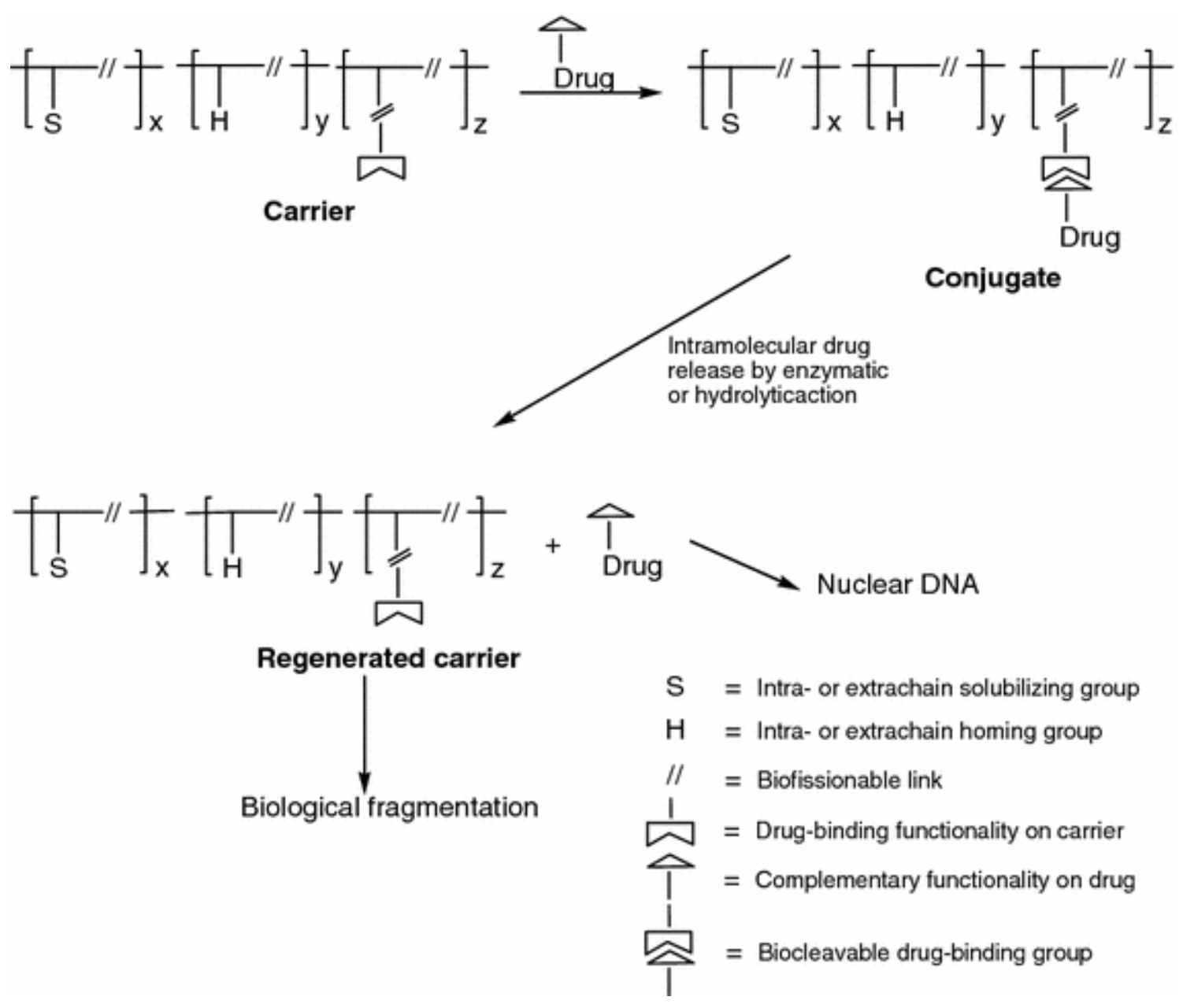

Scheme 1 Flow chart describing drug conjugate pharmacokinetics

\section{Carrier-bound Platinum Complexes: A General Survey}

As the conspicuous pharmacological deficiencies of the currently available platinum drugs are taken into account, conjugation of platinum compounds with suitably modified polymeric carriers will clearly lend itself as an immensely practicable tool geared to ameliorate those deficiencies. The literature indeed abounds with reports on the successful carrier-binding of a variety of platinum drug models. Earlier research efforts were aimed at the development of conjugates in which the two amine ligands, again in cisoid arrangement, were donated by the carrier polymer, either as main-chain components, or else as side-chain moieties. Scheme 2 depicts these structural arrangements ( $\mathrm{A}$ and $\mathrm{B}$, respectively. $\mathrm{R}$ = two-atom segment, preferentially ethylene). 


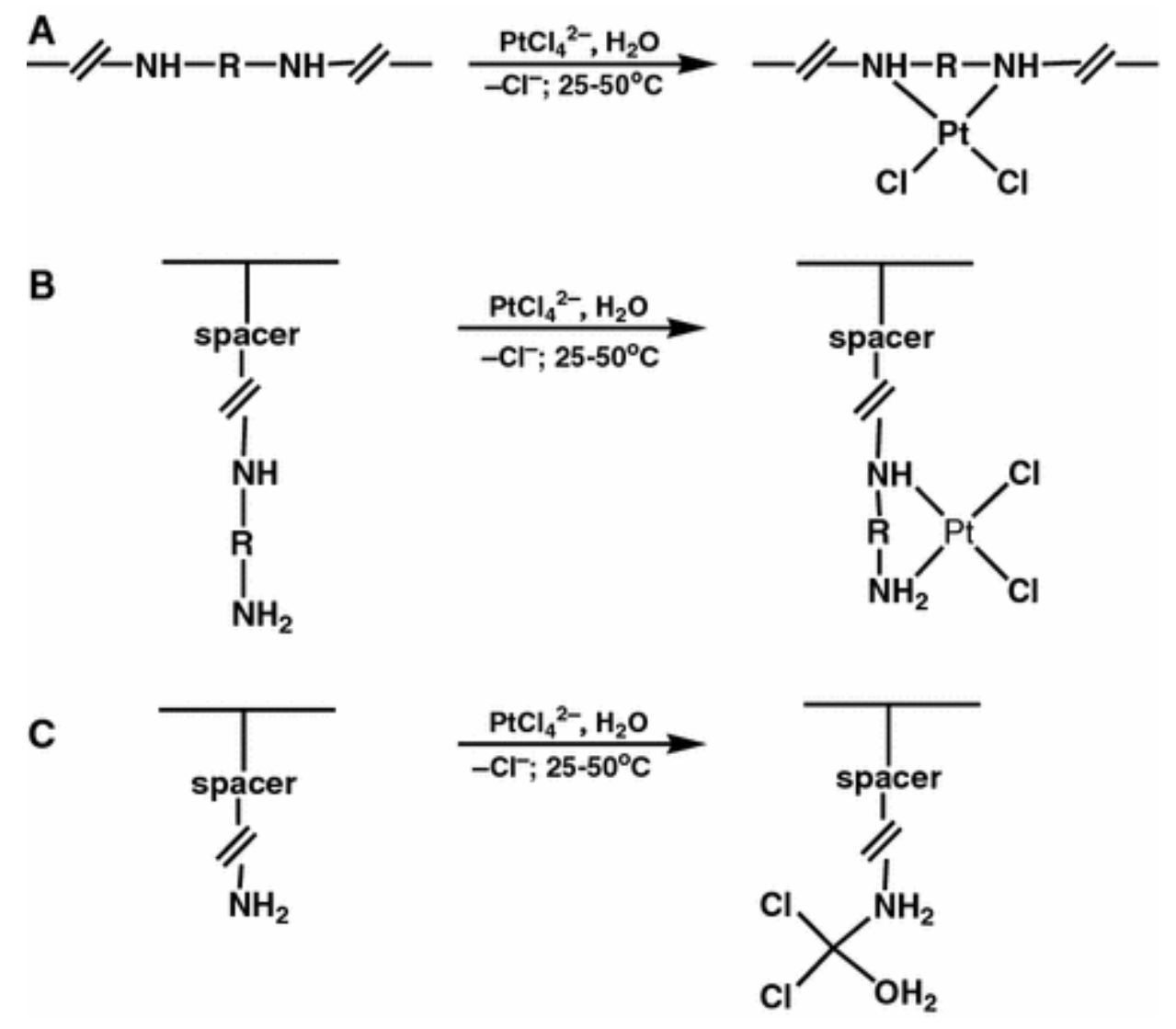

Scheme 2 Conjugates with platinum bound to carrier-attached mono- and diamine ligands

This discussion must include conjugates of the monoamine- $\mathrm{Pt}\left(\mathrm{OH}_{2}\right) \mathrm{C}_{2}$ type $(\mathrm{C})$, which in its non-polymeric form never entered the main stream of platinum drug research for lack of promising activity. In order to effectuate drug release from any such conjugate, care had to be taken to interpose suitable cleavage sites in backbone or side chain positions (typically a carboxamide group, marked here as $-I I-$ ) to allow the tightly bound amine ligands to come off along with the metal center as the non-polymeric drug entity. A plethora of publications, including major contributions from the author's laboratory, attest to the feasibility and resultant pharmaceutical improvements of this approach [3443]. Earlier reviews are available [17, 20,44, 45], and the recent report in a book chapter by Siegmann and Carraher [19] provides a summarizing and quite illuminating survey. As more recently the benefits of the carboplatin skeletal arrangement around the Pt atom became increasingly evident, the goals of polymer conjugation research shifted to a different drug binding strategy, whereby the metal is coordinated by two carrier-attached carboxylato ligands, thus permitting drug release via hydrolytically cleaved $-\mathrm{COO}^{-}$ leaving groups. While, in early work, these ligands were provided in non-specific geometry, researchers in more recent studies, taking advantage of the stabilizing effect achievable by Pt coordination through small-ring chelation, have moved away from undefined carboxylato binding in favor of well defined dicarboxylatoplatinum structures in which two carrier-attached carboxyl groups in fixed 1,1- or 1,2-geometry coordinate to the platinum atom with generation of chelate rings. For highest stability while the 
conjugate resides in the blood stream (serum $\mathrm{pH}$ 7.4), the rings are preferably restricted in size to 6-8 atomic constituents, where chelation integrity remains optimal. Principal release of the bioactive platinum complex occurs only in the more acidic environment $(\mathrm{pH} 5)$ of the endosomal space. The drawings in Scheme 3 for a representative side chain-coordinated dicarboxylatoplatinum chelate reflect this bonding and release pattern. (In this and the following carboxylato descriptions the group $\mathrm{COO}$ stands for $-(\mathrm{C}=\mathrm{O})-\mathrm{O}$ and thus represents a two-atom chelate ring constituent).
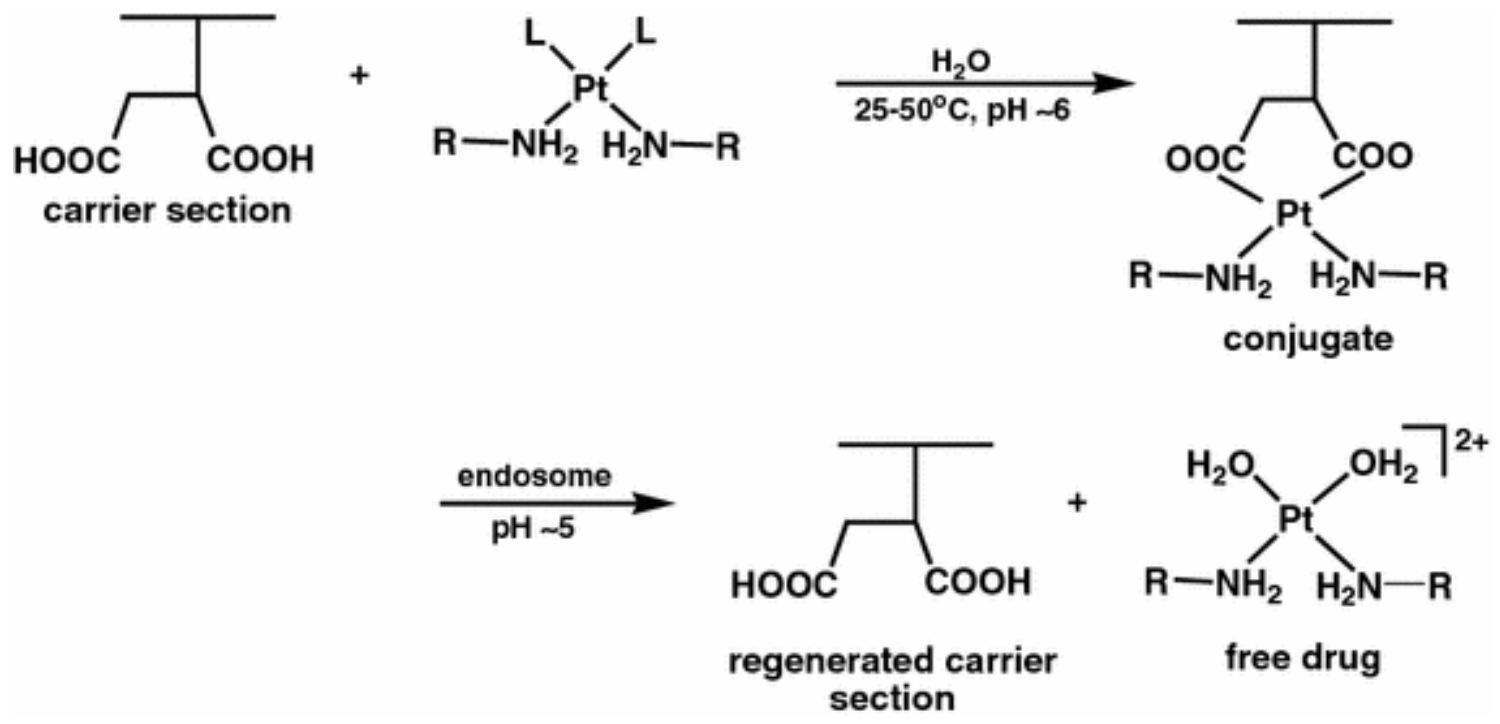

Scheme 3 Dicarboxylatometal chelation and endosomal drug release $(\mathrm{R}=\mathrm{H}$, alkyl; $\mathrm{L}=$ leaving group)

From the many reports of successful carrier platination via dicarboxylato chelation we single out the highly prolific investigations by Bilha Schechter and coworkers at the Weizmann Institute of Science, and by Ohya and Ouchi at Kansai University. Earlier studies at the Weizmann Institute comprised cisplatin incorporation into divinylethermaleic anhydride polymer, carboxymethyldextram, and other polycarboxylic acids, with generally rewarding in vitro and in vivo test results. Selected carriers of that project were coupled to an antibody with affinity to B lymphoma cells of the mouse, followed by platination as before, and the conjugates so modified displayed the expected selective cytotoxicity to the chosen lymphoma cancer [46, 47].

More recently, the group has developed avidinylated and streptavidinylated carboxymethyl-dextran-Pt conjugates for coupling with biotinylated antibodies [48]. Such biotin-avidin coupling can provide structures with improved target-homing capacity and resultant overall therapeutic effectiveness. The group's successful homing experiments, e.g. with biotinylated $\mathrm{mAB} 108$ antibody, attest to the practicability of this strategy, and further exciting findings by the Weizmann team may therefore be expected. The Kansai group investigated a large number of oxidized dextran derivatives platinated initially with cisplatin and subsequently with the more promising, and increasingly popular, trans-1,2-diaminocyclohexane-platinum (DACH-Pt) moiety [49]. The latter is commonly obtained now as the aquated nitrate salt, DACH-Pt $\left(\mathrm{NO}_{3}\right)_{2}($ Scheme 4). 

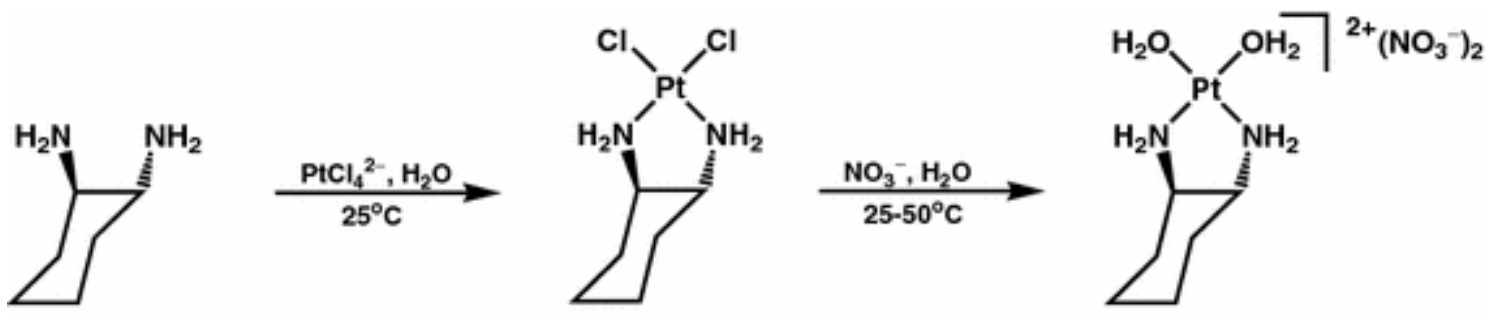

$\mathrm{DACH}-\mathrm{Pt}\left(\mathrm{NO}_{3}\right)_{2}$

Scheme 4 Formation of DACH-Pt( $\left(\mathrm{NO}_{3}\right)_{2}$ from trans-1,2-diaminocyclohexane

More lately, carboxymethylated and dicarboxymethylated dextrans were added by the group to the arsenal of carriers and were duly platinated. Cell culture tests performed on some of the platinated polymers indicated these to possess about the same in vitro cytotoxicity as exhibited by the free DACH-Pt agent, while showing considerably extended serum life-times. The group also observed high in vivo cytotoxic activity of selected polymers against implanted Colon 26 cancer cells. In follow-on studies, ethylene oxide polymers modified with malonic acid terminals served as the carrier structures, to be platinated with cisplatin. While showing slightly decreased cytotoxic activity relative to cisplatin, the conjugates retained that activity over an extended life-time in serumcontaining medium $[50,51]$. Separately, the Kansai group synthesized dicarboxymethyldextrans and malonic acid-terminated ethylene oxide polymers, each one modified with branched galactose units and, lastly, platinated with cisplatin. The branched ("antennary"-type) galactose residues in those conjugates served as devices for the targeting to liver tissue. Cell-specific cytotoxicity against Hep G2 human hepatoma cells was indeed observed, reflecting the soundness of this approach [52, 53]. For a more indepth treatment of these studies and others by-passed in the present text the reader is, once again, referred to the chapter by Siegmann-Louda and Carraher [19].

\section{Carrier-bound cis-Dicarboxylato-dach-pt Compounds: Development Work in the Authors' Laboratory}

\subsection{Results and Discussion}

Exploratory investigations in the authors' laboratory, dating back to the 'Nineties, were aimed at studying the feasibility of platinum binding through chelation with pairs of carboxylato ligands donated by synthetic carrier polymers providing biodegradability and water solubility, while offering a wide range of structural variability. The two polymer classes chosen, both featuring linear polyamide-type main chains, were (1) polyaspartamides derived from polysuccinimide by nucleophilic ring-opening steps, and (2) polyamidoamines obtained by Michael addition polymerization of bisacrylamides with primary and/or secondary amine comonomers. The polyaspartamides were pioneered in the 'Seventies by Neri and Antoni [54, 55] and others [56-58], whereas 
Ferruti's laboratory $[59,60]$ initiated and promoted work on the polyamidoamines. Subsequently, the two carrier classes were further developed by our group [61, 62]. Both polymer types, with exemplifying structures presented in some of the following reaction schemes, indeed offer immense possibilities for variation of backbone and side-chain construction for the purpose of introducing units that would provide solubilizing, targeting, and drug-binding functionalities in addition to required cationicity, and it is on the strength of these benefits that the two polymer classes have earned the title of "work horse" carriers and are still the carriers of choice in this laboratory. Early platination studies produced conjugates featuring metal chelation patterns in accord with Scheme 3 ( $\mathrm{R}, \mathrm{R}=$ trans-1,2-diaminocyclohexane). A representative polyaspartamide conjugate gave cytotoxicity data against the (sensitive) HeLa human cervical adenocarcinoma and the (resistant) Colo 320 DM human intestinal cancer cell lines that proved to be ever so slightly superior to the cisplatin standard. Prompted by this initial finding, a major synthesis and bio-evaluation program was initiated, which is still ongoing, and salient results on selected aspects are presented in the subsequent sections.

The first phase of the project covered the synthesis of the requisite carrier polymers. Polyaspartamides 1-3 were prepared from polysuccinimide in a stepwise modality by the time-proven [63] general methodology (Scheme 5).
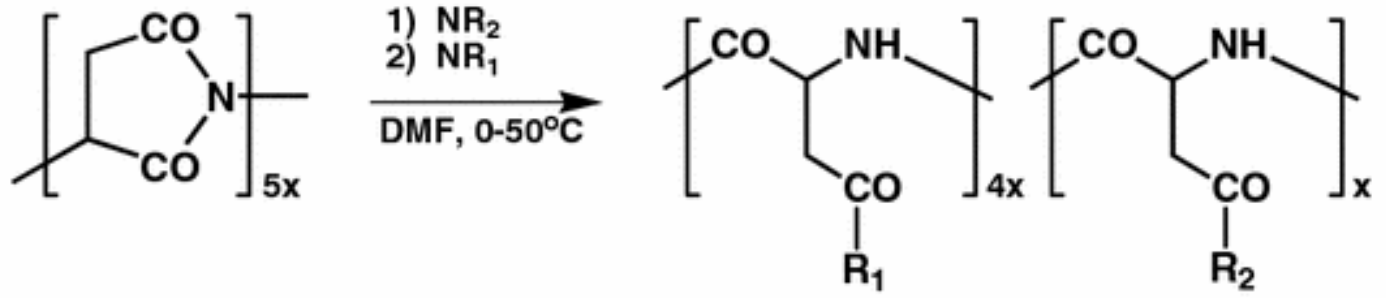

Carrier designation

$\mathbf{R}_{1}$

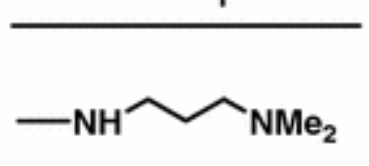

1

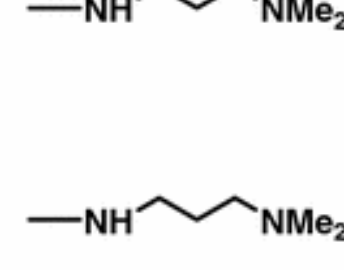

2

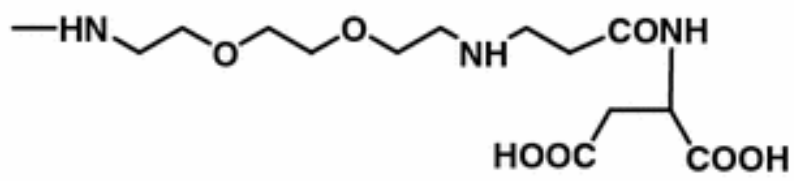

3<smiles>CNCCCNCCCNCCC(=O)NC(CC(=O)O)C(=O)O</smiles>

Scheme 5 Polyaspartamide carriers 1, 2, and 3 
The key monomers employed here and later on as the carboxylato ligand donors, $\mathrm{N}-(4,7-$ diaza-6(5)-methyl-heptanoyl)aspartic acid, $N$-(4,13-diaza-7,10-dioxa-tridecanoyl)aspartic acid, and $N$-(4,8-diaza-octanoyl)aspartic acid (Fig. 2a-c, in that order), were prepared by Michael addition of diamines across the active double bond in acryloylaspartic acid as described previously [64].
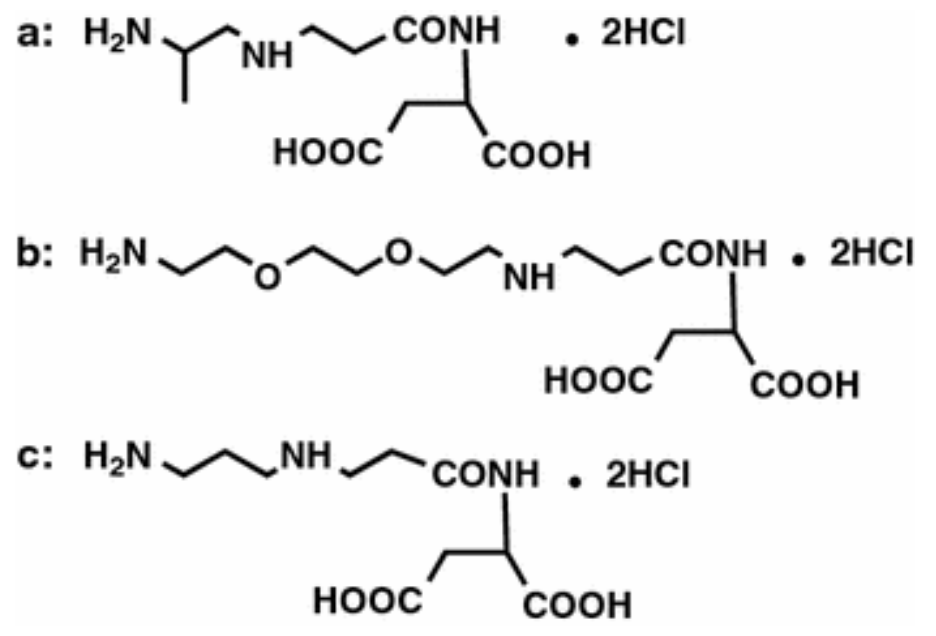

Fig. 2 Amine-functionalized aspartic acid derivatives

For the preparation of the polymeric amidoamine carriers $\mathbf{4}$ and $\mathbf{5}$ (Scheme 6) methylenebisacrylamide was copolymerized with the hydrosolubilizing primary amine, $\mathrm{N}, \mathrm{N}$-dimethyl-1,3-propanediamine, and the carboxylato-donating comonomers, aspartic acid (giving 4) or derivative a Fig. 2 (giving 5). The molar reactant ratio shown in the equation leading to $\mathbf{4}$ corresponds to theoretical stoichiometry. In practice, however, because of the very poor amine nucleophilicity in aspartic acid, use of equimolar quantities of this acid and the amine comonomer resulted in a polymer composition as shown, with the solubilizing unit in 1.5-fold excess over the dicarboxyl-functionalized unit. No such problems were encountered with the aspartic acid derivative a leading to $\mathbf{5}$, being equipped with a less sterically encumbered and, hence, more nucleophilic primary aminoalkyl terminal. 


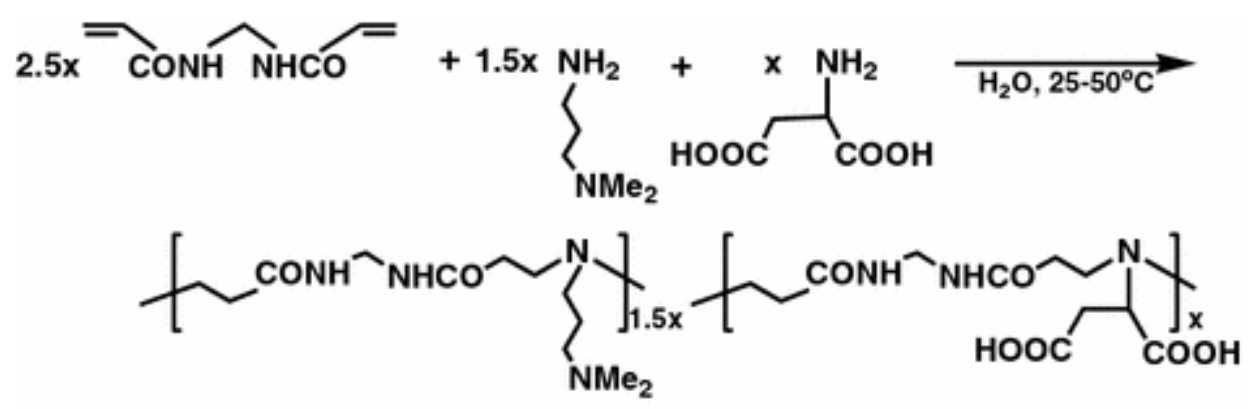

4

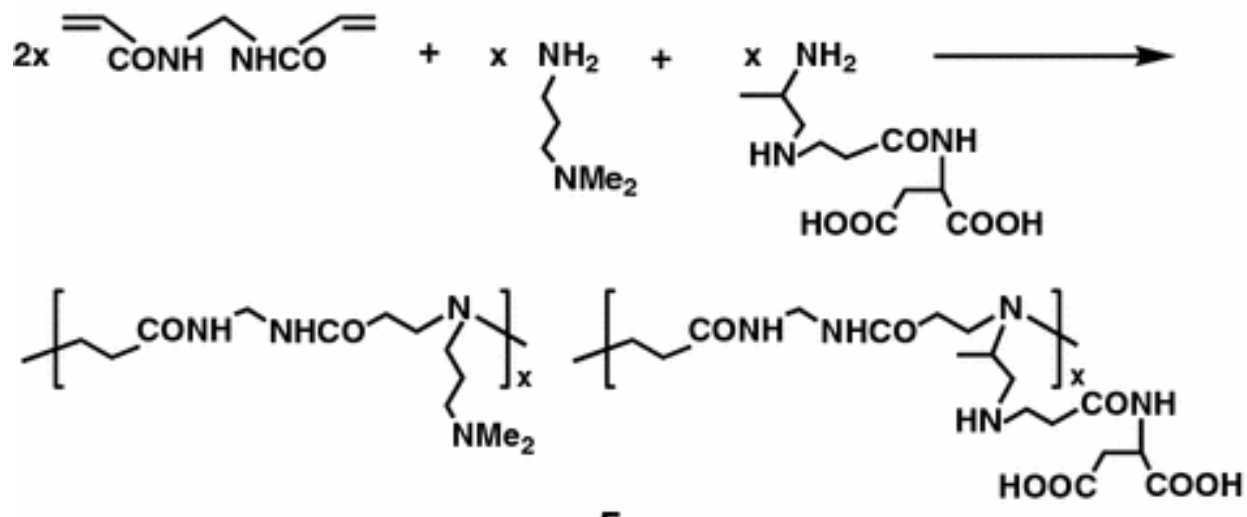

5

Scheme 6 Polyamidoamine carriers 4 and 5

Both 4 and 5 had been obtained in an earlier study [64] and were sampled from those products for the present work..

All carriers were routinely fractionated by dialysis and isolated by freeze-drying as watersoluble solids amenable to spectroscopic characterization.

In the project's second phase, the pre-synthesized carriers 1-5 were platinated in aqueous phase at $25-50{ }^{\circ} \mathrm{C}, \mathrm{pH} 5$, with the aid of the DACH-Pt platination agent (Scheme 4), giving conjugates 1Pt-5Pt (Schemes 7 and 8 ). The unit's proportions along the chain in these carrier-bound platinum compounds, calculated from observed percentage $\mathrm{Pt}$ contents, clearly demonstrate the difficulty of achieving quantitative metal incorporation under the non-aggressive metalation conditions of those reactions. More forcing conditions, on the other hand, had to be avoided in order to exclude, or at least minimize, hydrolytic degradation with loss of structural integrity, notably regeneration of the monomeric platinum complex. As a consequence of such precautionary methodology, the product polymers, notably the sterically less yielding polyaspartamides, contain unmetallated dicarboxylate units in rather sizeable proportions. These structural arrangements, however, are not expected significantly to affect biomedical performance, which is solely assessed on the basis of actual Pt contents. 


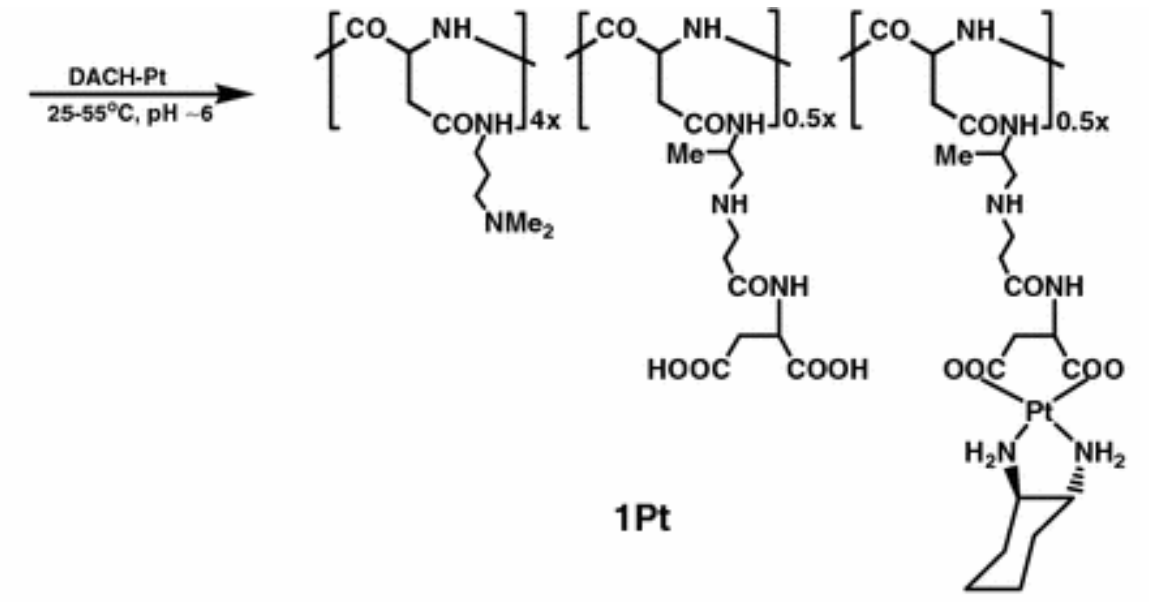

$2 \underset{25-55^{\circ} \mathrm{C}, \mathrm{pH} \sim 6}{\stackrel{\mathrm{DACH}-\mathrm{Pt}}{\longrightarrow}}$<smiles>CC(C)(C)O[13C](C)(C)CC1CO1</smiles>

2Pt

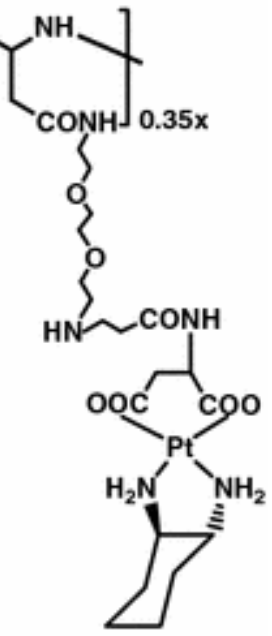

$3 \underset{25-55^{\circ} \mathrm{C}, \mathrm{pH} \sim 6}{\stackrel{\mathrm{DACH}-\mathrm{Pt}}{\longrightarrow}}$<smiles>CN(C)CCNC(C)(C)NC(CC(=O)O)OCC1CC1</smiles>

3Pt

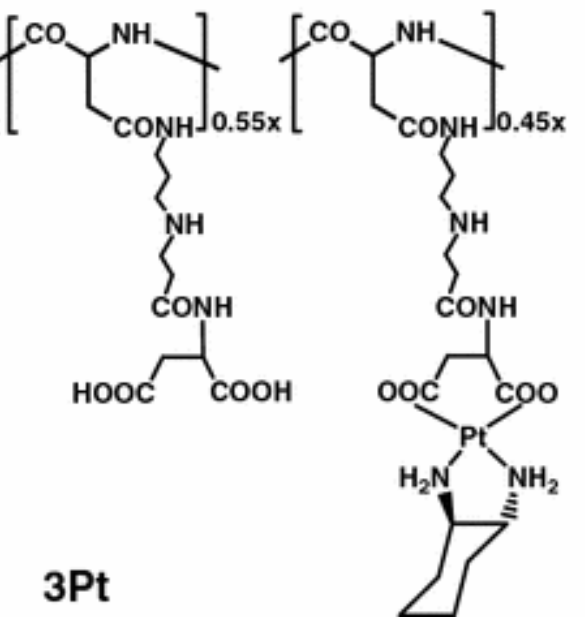

Scheme 7 Polyaspartamide-based platinum conjugates 1Pt-3Pt 


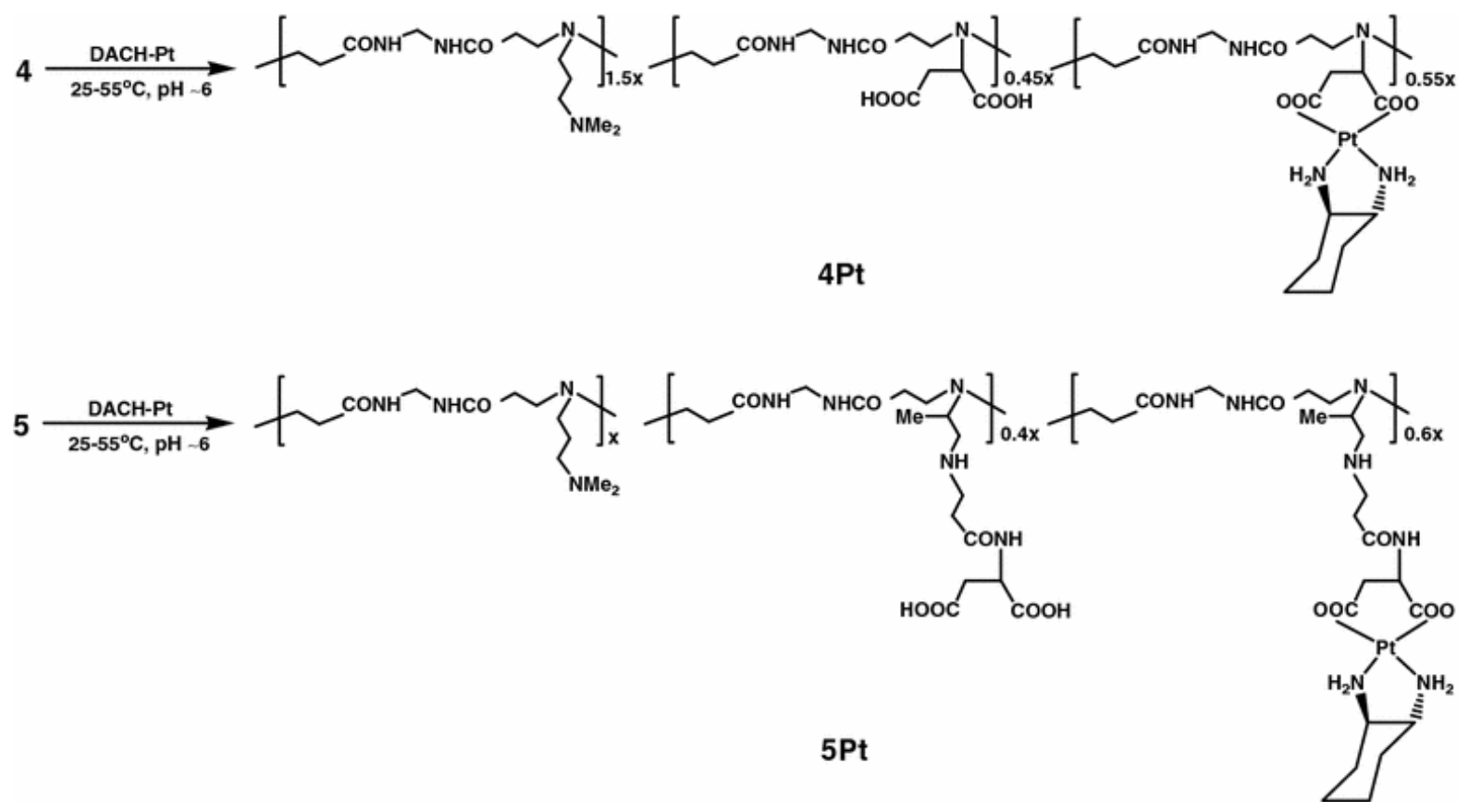

Scheme 8 Poly(amidoamine)-based platinum conjugates $4 \mathbf{P t}$ and $\mathbf{5 P t}$

For comparison of bio-performance data, we have included the synthesis and platination of simple polyaspartamide-based monoamine- and diamine-coordinated platinum conjugates 6Pt-8Pt (Scheme 9). These polymers are devoid of the dicarboxylatometal chelate ring system and instead conform to Scheme 2 (c and b, respectively). 

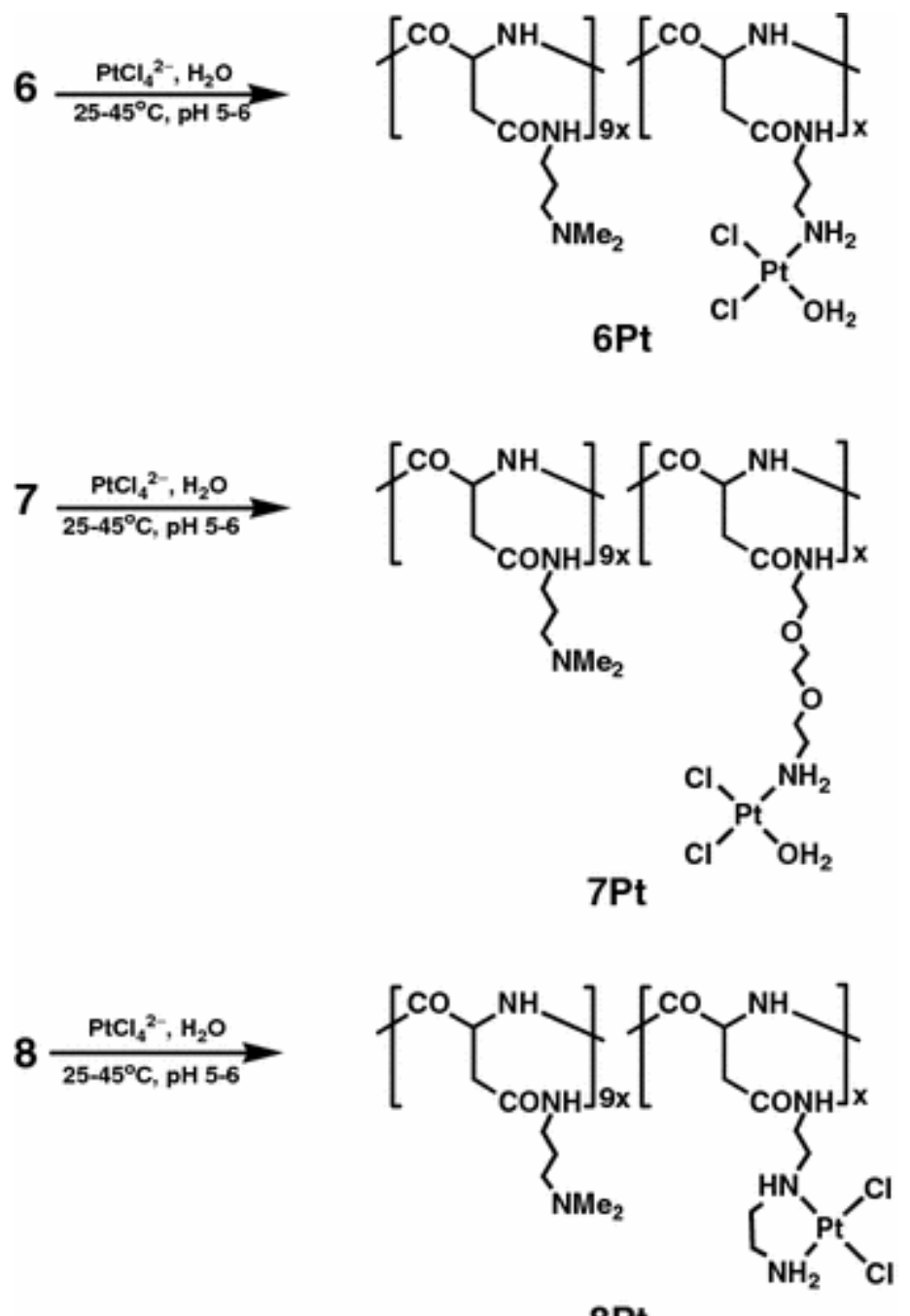

8Pt

Scheme 9 Platination of monoamine- and diamine-functionalized carriers

\section{Bio-evaluation in Cell Culture Tests: Preliminary Results}

Conjugates 1Pt-8Pt were bio-evaluated in vitro against the HeLa and Colo 320 cancer cell lines. The HeLa line, a human cervical adenocarcinoma, is frequently used as a convenient "benchmark" cell culture, being comparatively sensitive to the common cancer lines employed in in vitro screens. In contrast, Colo 320, representing a human intestinal cancer, is regarded as a distinctly drug-resistant cell line. Also included in this test series are the human ovarian cancer A2780 and its cisplatin-resistant subline, A2780cis. The four cell lines cited thus represent a reasonably broad spectrum of antiproliferative activities, and their response to drug action will therefore reflect a sound cytotoxic activity profile.

With the aid of standard cell culture testing methodology [65], samples of 1Pt-8Pt, tested against the aforementioned cell lines, gave the $\mathrm{IC}_{50}$ valued listed in Table 1 $\left(\mathrm{IC}_{50}=\right.$ drug concentration required to achieve $50 \%$ cell killing relative to a drug-free 
control). The table also provides comparative data on free cisplatin included here as a non-polymeric standard.

Table 1 Antiproliferative activity of platinum conjugates

\begin{tabular}{|c|c|c|c|c|c|}
\hline \multirow{2}{*}{$\begin{array}{l}\text { Conjugate } \\
\text { Designation }\end{array}$} & \multirow{2}{*}{$\% \mathrm{Pt}^{\mathrm{b}}$} & \multicolumn{4}{|c|}{$\mathrm{IC}_{50}(\mu \mathrm{g} \mathrm{Pt} / \mathrm{mL})^{\mathrm{a}}$} \\
\hline & & HeLa & Colo 320 DM & A2780 & A2780-cis ${ }^{c}$ \\
\hline $1 \mathrm{Pt}$ & 7.3 & 0.00032 & 0.027 & 0.0044 & $0.014(3.2)$ \\
\hline $2 \mathrm{Pt}$ & 5.35 & 0.00076 & 0.13 & 0.041 & $0.014(0.3)$ \\
\hline $3 \mathbf{P t}$ & 7.1 & 0.00012 & 0.026 & 0.035 & $0.035(1.0)$ \\
\hline $4 \mathbf{P t}$ & 13.1 & 0.0043 & 0.505 & 0.0055 & $0.041(7.4)$ \\
\hline $5 \mathrm{Pt}$ & 14.0 & 0.00091 & 0.19 & 0.009 & $0.0067(0.75)$ \\
\hline $6 \mathrm{Pt}$ & 8.3 & 1.77 & 1.42 & 1.21 & $1.89(1.6)$ \\
\hline $7 \mathrm{Pt}$ & 8.9 & 2.98 & 6.19 & 2.33 & $2.71(1.2)$ \\
\hline $8 \mathbf{P t}$ & 8.0 & 6.52 & 9.66 & 1.20 & $1.83(1.5)$ \\
\hline Cisplatin & & 0.052 & 0.125 & 0.017 & $0.063(3.7)$ \\
\hline
\end{tabular}

${ }^{\mathrm{a}} \mathrm{IC}_{50}$ defined here as the drug concentration, in $\mu \mathrm{g} \mathrm{Pt} / \mathrm{mL}$, required to achieve $50 \%$ cell killing relative to a drug-free control

${ }^{\mathrm{b}}$ Platinum content, by mass, found

${ }^{\mathrm{c}}$ In parentheses, resistance factor, defined as $\mathrm{IC}_{50}$ (resistant line) over $\mathrm{IC}_{50}$ (sensitive line)

The reader should be reminded at this point that, as per definition, the $\mathrm{IC}_{50}$ value will decrease with increasing cytotoxicity and vice versa. Cursory examination of the tabulated data thus immediately reflects a significant superiority in cytotoxic activity of the group of dicarboxylatometal-chelated conjugates (1Pt-5Pt) over the conjugates featuring simple amine- or diamine-coordinated platinum $(6 \mathbf{P t}-\mathbf{8 P t})$. In fact, crude averaging in the HeLa column of the data for 1Pt-5Pt $\left(1.28 \times 10^{-3}\right)$ and for Pt6-Pt8 (3.76) indicates the former group of conjugates to be some thousand times more active than the latter group when tested against HeLa. Although a considerably larger number of samples of both groups will be required to arrive at an accurate figure, it is obvious even from these limited data that the polymeric dicarboxylato-chelated platinum compounds represent a sizeable advantage over the conjugates in which the metal is polymer-bound via amine ligands. Smooth hydrolytic drug liberation from the carrier in the conjugates 1Pt-5Pt, as compared to the more retarded hydrolytic or enzymatic fission of the amidetype interconnectors in $\mathbf{6 P t}-\mathbf{8 P t}$, may explain this enormous difference in cell killing performance.

Let us look now specifically at the $\mathrm{IC}_{50}$ values within the group of dicarboxylato-chelated polymers (1Pt-5Pt). Notwithstanding the small number of samples tested, both the aspartamide (1Pt-3Pt) and the amidoamine (4Pt, 5Pt) polymer types show reasonably comparable cytotoxic performance. This may be rationalized in terms of identical drug release mechanisms operative in the two groups. 
Generally waning activity is observed as one goes from the HeLa to the Colo column. Most dramatic is the change experienced by $\mathbf{2 P t}$, for which $\mathrm{IC}_{50}$ increases from 0.00076 to 0.13 . While this trend is consistent with the known drug resistance of the Colo line, it clearly shows, pending further large-scale testing, that these three conjugates as a class must be regarded as an inadequate choice for the treatment of colorectal malignancies. (Interestingly, no such trend is apparent for the second group of conjugates, where within experimental error limits, substantially unchanged cell killing behavior is observed.) Comparing now the A2780 and A2780-cis columns, one finds most of the conjugates to elicit reduced cisplatin cross-resistance, their resistance factors $\left(\mathrm{IC}_{50}\right.$ against resistant line over $\mathrm{IC}_{50}$ against sensitive line) being smaller on average than that of free cisplatin. Resistance factors $<1$ for $\mathbf{2 P t}$ and $\mathbf{5 P t}$ in fact show these two polymers ever so slightly to excel in reactivity against the resistant line as compared to the sensitive one.

It is instructive, lastly, to compare the $\mathrm{IC}_{50}$ data for $\mathbf{1 P t}-\mathbf{5 P t}$ in the four listed columns with those for the cisplatin standard. On average, the conjugates possess cytotoxic activities roughly equal (Colo, A2780) or superior (HeLa, A2780-cis) to those of the standard. These findings are critically relevant if it is recognized that, contrasting with the monomeric cisplatin drug, the very significant additional pharmacological benefits displayed by drugs in the polymer-bound state, such as increased serum residence time, bioavailability, and target cell affinity, paired with reduced systemic toxicity, reveal themselves only in the living organism (see Section 2) as monitored by in vivo screens. They will not, hence, be obvious from cell culture tests. These additional pharmacological advantages must be seen in combination with the discussed in vitro results for a true appraisal of the reported conjugates' overall bioactivity profiles.

\subsection{Experimental Part}

\subsubsection{General Procedures}

Proton NMR spectra (400 MHz; selected band groups only) were taken on $\mathrm{D}_{2} \mathrm{O}$ solutions (two separate recordings for each conjugate; data averaged for evaluation). Chemical shifts, $\delta / \mathrm{ppm}$, were referenced against sodium 3-(trimethylsilyl)-2,2,3,3- $\mathrm{d}_{4}$-propionate as internal standard; integration error limits $\pm 10 \%$. Spectral solutions were adjusted to $\mathrm{pD}$ 10 prior to recording in order to prevent spurious protonation. Polymer solutions were dialyzed in cellulose membrane tubing, types Spectra/Por 4 and Spectra/Por 6 (wet tubing), with mass-average molecular mass cut-off limits of 12,000-14,000 and 25,000, respectively. Operations were performed against several batches of stirred deionized $\mathrm{H}_{2} \mathrm{O}$, with $\mathrm{pH}$ adjusted as required. Freeze-drying operations were carried out with the aid of a Virtis Bench Top 3 freeze-drier $\left(30^{\circ} \mathrm{C}, 0.1\right.$ torr). Metal-free polymers were routinely post-dried in a Sartorious Thermo Control Infrared Drying System (heating program, $2 \times 5 \mathrm{~min}$ at $65^{\circ} \mathrm{C}$ ). Analytical samples were additionally dried in an Abderhalden tube for 2 days at $50-60{ }^{\circ} \mathrm{C}$ under reduced pressure. Cell culture tests were conducted as previously reported [65].

\subsubsection{Solvents, Reagents, and Monomeric Reactants}

$N, N$-Dimethylformamide (DMF) was dried over Molecular Sieves 4A and distilled under reduced pressure in a faint stream of $\mathrm{N}_{2}$, a forerun of $5 \%$ being discarded. Deionized $\mathrm{H}_{2} \mathrm{O}$ 
was used in preparative operations. Commercially supplied (Fluka AG, Aldrich Chemie $\mathrm{GmbH})$ chemicals, reagent grade, were used as received. These included $3(N, N-$ dimethylamino)propylamine, 1,2-diaminopropane, 1,3-diaminopropane, diethylenetriamine, ethylenedioxy-O,O'-bis(2-ethylamine). Methylenebisacrylamide was recrystallized from water in the presence of $0.5 \%$ by mass of hydroquinone inhibitor. The key aspartic acid-derived monomer a (Fig. 2) was prepared as the dihydrochloride by the recently published procedure [64]. For the synthesis of the monomers b and c (Fig. 2), $N$ (4,13-diaza-7,10-dioxa-tridecanoyl)aspartic acid and $N$-(4,8-diaza-octanoyl)aspartic acid, the procedures employed in that paper for the preparation of the amidoglycolic acid derivative, there designated $\mathbf{1 3}$ and $\mathbf{1 2}$ were used in the present work, except that equivalent amounts of $\mathrm{N}$-acryloylaspartic acid were substituted for acrylamidoglycolic acid. The compounds, again, were isolated as the dihydrochloride salts.

\subsubsection{Polymeric Educts and Carriers}

Amounts of polymeric educts and products are given as base moles and, thus, refer to the simplest recurring units defined by carrier structures $\mathbf{1}-\mathbf{5}$, all normalized to $\mathrm{x}=1$.

\subsubsection{Poly-DL-succinimide}

This educt polymer was prepared by the published procedure $[55,63] ; \mathrm{M}_{\mathrm{w}} \approx 29,000$. The finely pulverized polymer was predried in an Abderhalden tube $\left(1 \mathrm{~d}, 75^{\circ} \mathrm{C}\right)$ under reduced pressure prior to use.

Carrier 1. To the stirred solution of polysuccinimide, $0.48 \mathrm{~g}(4.9 \mathrm{mmol})$, in $15 \mathrm{~mL}$ of DMF was added $N$-(4,7-diaza-6(5)-methyl-heptanoyl) aspartic acid dihydrochloride, $0.76 \mathrm{~g}(2.9 \mathrm{mmol})$, and trimethylamine, $1.62 \mathrm{~mL}(11.6 \mathrm{mmol})$. The resulting suspension, saturated with $\mathrm{N}_{2}$, was stirred for $2 \mathrm{~d}$ at ambient temperature. 3- $(N, N-$ dimethylamino)propylamine, $0.48 \mathrm{~mL}$ (3.9 mmol), dissolved in $3 \mathrm{~mL}$ of DMF, was added dropwise with stirring, and upon re-saturation with $\mathrm{N}_{2}$ the suspension was stirred for another $1 \mathrm{~d}$ at room temperature. Filtration was followed by volume reduction of the filtrate to ca. $5 \mathrm{~mL}$ under reduced pressure at $50-60{ }^{\circ} \mathrm{C}$, and the polymeric product was precipitated with $\mathrm{Et}_{2} \mathrm{O} /$ hexane, $2: 1$ by vol. $(15 \mathrm{~mL})$. Upon washing with hot toluene and acetone, the residue was redissolved in $10 \mathrm{~mL}$ of water. Upon $\mathrm{pH}$ adjustment from ca. 12 to $8(\mathrm{HC} \ell)$, the solution was dialyzed for $2 \mathrm{~d}$ in Spectra/Por 4 and another $2 \mathrm{~d}$ in Spectra/Por 6 tubing. Freeze-drying of the retentate and IR post-drying gave $0.1254 \mathrm{~g}$ (22.4\%) of water soluble, solid 1.

${ }^{1} \mathrm{H}$ NMR $\left(\mathrm{D}_{2} \mathrm{O}\right), \delta / \mathrm{ppm}: 3.3-3.2,10.7 \mathrm{H}(9 \mathrm{H} ; \mathrm{CONHCH}) ; 2.2,\left(8 \mathrm{H} ; \mathrm{CH}_{2} \mathrm{~N}\left(\mathrm{CH}_{3}\right)_{2}\right) ; 2.1$, $\left(24 \mathrm{H} ; \mathrm{N}\left(\mathrm{CH}_{3}\right)_{2}\right) ; 1.8,\left(8 \mathrm{H} ; \mathrm{CH}_{2} \mathrm{CH}_{2} \mathrm{CH}_{2}\right) ; 1.1,3 \mathrm{H}\left(3 \mathrm{H} ; \mathrm{CHCH}_{3}\right)$.

Carrier 2. By the procedure leading to $\mathbf{1}$, this carrier was prepared from polysuccinimide, $0.60 \mathrm{~g}(6.1 \mathrm{mmol})$, in $15 \mathrm{~mL}$ of DMF, treated with $\mathrm{N}$-(4,13-diaza-7,10-dioxa-

tridecanoyl)-aspartic acid dihydrochloride, $1.23 \mathrm{~g}(3.7 \mathrm{mmol})$, and triethylamine, $2.10 \mathrm{~mL}$ (14.8 mmol). 3-( $N, N$-Dimethylamino)propylamine, $0.62 \mathrm{~mL}(4.9 \mathrm{mmol})$, in $3 \mathrm{~mL}$ of DMF was then added to the suspension, and the mixture was treated and worked up as before, giving $0.494 \mathrm{~g}(32.9 \%)$ of 2 as a water soluble solid. 
${ }^{1} \mathrm{H}$ NMR $\left(\mathrm{D}_{2} \mathrm{O}\right), \delta / \mathrm{ppm}: 3.8-3.6,7.1 \mathrm{H}\left(8 \mathrm{H} ; \mathrm{CH}_{2} \mathrm{OCH}_{2} \mathrm{OCH}\right) ; 3.3-3.2,9.4 \mathrm{H}(10 \mathrm{H}$; $\left.\mathrm{CONHCH}_{2}\right) ; 2.2,8.2 \mathrm{H}\left(8 \mathrm{H} ; \mathrm{CH}_{2} \mathrm{~N}\left(\mathrm{CH}_{3}\right)_{2}\right) ; 2.1,26 \mathrm{H}\left(24 \mathrm{H} ; \mathrm{N}\left(\mathrm{CH}_{3}\right)_{2}\right) ; 1.8-1.7,8 \mathrm{H}(8 \mathrm{H}$; $\mathrm{CH}_{2} \mathrm{CH}_{2} \mathrm{CH}_{2}$ ).

Carrier 3. The analogous procedure, yet with $N$-(4,8-diaza-octanoyl)aspartic acid dihydrochloride (c in Scheme 2) in place of b, gave carrier 3 in 33\% yield.

${ }^{1} \mathrm{H}$ NMR $\left(\mathrm{D}_{2} \mathrm{O}\right)$, $\delta$ /ppm: 3.3-3.2, $10 \mathrm{H}\left(10 \mathrm{H} ; \mathrm{CONHCH}_{2}\right) ; 2.2,8.3 \mathrm{H}\left(8 \mathrm{H} ; \mathrm{CH}_{2} \mathrm{~N}\left(\mathrm{CH}_{3}\right)_{2}\right)$; $2.1,25 \mathrm{H}\left(24 \mathrm{H} ; \mathrm{N}\left(\mathrm{CH}_{3}\right)_{2}\right) ; 1.7-1.5,10 \mathrm{H}\left(10 \mathrm{H} ; \mathrm{CH}_{2} \mathrm{CH}_{2} \mathrm{CH}_{2}\right)$.

Carriers 4 and 5. The polymers were obtained from a preceding project [64], there designated as Polymer 3 and Polymer 4, respectively.

\subsubsection{Polymeric Platinum Conjugates}

As before, amounts of educts and products are given as base moles and thus refer to the simplest recurring units defined by conjugate structures $\mathbf{1 P t}-\mathbf{8 P t}$ normalized to $\mathrm{x}=1$. The DACH-Pt $\left(\mathrm{NO}_{3}\right)_{2}$ platination agent, trans-1,2-diaminocyclohexanediaquaplatinum(II) dinitrate (Scheme 4), was prepared as described [66]. Anal. calcd. for $\mathrm{C}_{6} \mathrm{H}_{18} \mathrm{~N}_{4} \mathrm{O}_{8} \mathrm{Pt}$ (469.3): Pt, 41.6\%. Found: Pt, $42.1 \%$.

Conjugate 1Pt . To the $\mathrm{N}_{2}$-saturated solution of carrier 1, $196 \mathrm{mg}(0.17 \mathrm{mmol})$ in $5 \mathrm{~mL}$ of water was added DACH-Pt( $\left(\mathrm{NO}_{3}\right)_{2}, 98 \mathrm{mg}(0.21 \mathrm{mmol})$, dissolved in $5 \mathrm{~mL}$ of water. Upon resaturation with $\mathrm{N}_{2}$, the solution protected from light, was stirred for $3 \mathrm{~d}$ at room temperature and for another $2 \mathrm{~h}$ at $45.47{ }^{\circ} \mathrm{C}$. During this period, the $\mathrm{pH}$ dropped from ca. 6.5 to 5.5 and was maintained at that level. The filtered solution was dialyzed for $2 \mathrm{~d}$ in Spectra/Por 4 tubing, and the retentate was freeze-dried, to give $0.14 \mathrm{~g}(33.7 \%)$ of watersoluble, solid 1Pt.

Anal. calcd. for $\left(\mathrm{C}_{53} \mathrm{H}_{96} \mathrm{~N}_{17} \mathrm{O}_{15} \mathrm{Pt}_{0.5}\right)_{\mathrm{n}}(1309)_{\mathrm{n}}: \mathrm{Pt}, 7.5 \%$. Found: Pt, 7.3\%.

Conjugate 2Pt. An experiment conducted as in the foregoing, yet with Carrier 2 in place of $\mathbf{1}$, gave water-soluble conjugate $\mathbf{2 P t}$ in $33 \%$ yield.

Anal. calcd. for $\left(\mathrm{C}_{55.1} \mathrm{H}_{100.2} \mathrm{~N}_{16.7} \mathrm{O}_{17} \mathrm{Pt}_{0.35}\right)_{\mathrm{n}}(1337)_{\mathrm{n}}$ : $\mathrm{Pt}$, 5.1\%. Found: $\mathrm{Pt}, 5.35 \%$. Conjugate 3Pt. By the standard procedure used in the two forgoing experiments, with carrier $\mathbf{3}$ as the substrate, there was obtained water-soluble conjugate $\mathbf{3 P t}$ in a yield of $53 \%$.

Anal. calcd. for $\left(\mathrm{C}_{52.7} \mathrm{H}_{95.4} \mathrm{~N}_{16.9} \mathrm{O}_{15} \mathrm{Pt}_{0.45}\right)_{\mathrm{n}}(1293.6)_{\mathrm{n}}$ : $\mathrm{Pt}, 6.8 \%$. Found: $\mathrm{Pt}, 7.1 \%$. Conjugate 4Pt. Carrier 4, platinated as in the foregoing experiments, was converted to water-soluble conjugate $\mathbf{4 P t}$, in a yield of $42 \%$.

Anal. calcd. for $\left(\mathrm{C}_{32.3} \mathrm{H}_{59.6} \mathrm{~N}_{10.1} \mathrm{O}_{9} \mathrm{Pt}_{0.55}\right)_{\mathrm{n}}(840.77)_{\mathrm{n}}$ : $\mathrm{Pt}, 12.8 \%$. Found: $\mathrm{Pt}, 13.1 \%$. Conjugate 5Pt. Platination of carrier 5 as before provided conjugate 5Pt in a yield of $36 \%$.

Anal. calcd. for $\left(\mathrm{C}_{32.6} \mathrm{H}_{60.2} \mathrm{~N}_{10.2} \mathrm{O}_{9} \mathrm{Pt}_{0.6}\right)_{n}(856.13)$ : $\mathrm{Pt}, 13.7 \%$. Found: $\mathrm{Pt}, 14.0 \%$. 
Conjugate 6Pt. The carrier polymer for this conjugate was prepared essentially as described previously [43]. Briefly, with strict moisture preclusion, the solution of 3(dimethylamino)propylamine, $1.84 \mathrm{~g}(18 \mathrm{mmol})$, in $10 \mathrm{~mL}$ of DMF was added with rapid stirring to polysuccinimide, $1.94 \mathrm{~g}(20 \mathrm{mmol})$, dissolved in $15 \mathrm{~mL}$ of the same solvent. After saturation with $\mathrm{N}_{2}$, the resulting solution was stirred in the stoppered vessel for $8 \mathrm{~h}$ at ambient temperature; it was then added dropwise to the solution of 1,3diaminopropane, $445 \mathrm{mg}(6 \mathrm{mmol})$, in $15 \mathrm{~mL}$ of DMF, precooled to $0{ }^{\circ} \mathrm{C}$. Upon resaturation with $\mathrm{N}_{2}$, the solution was stirred for $24 \mathrm{~h}$ at ice-bath temperature and for another $8 \mathrm{~h}$ at room temperature. Volume reduction to ca. $15 \mathrm{~mL}$ by rotary evaporation was followed by precipitation of the polymeric product with $50 \mathrm{~mL}$ of $\mathrm{Et}_{2} \mathrm{O}$-hexane (2:1). The precipitate was thoroughly washed with warm hexane and acetone for removal of monomeric adherents and was dialyzed in $20 \mathrm{~mL}$ of water at $\mathrm{pH} 7-8$ successively for 2 days in Spectra/Por 4 and another 2 days in Spectra/Por 6 tubing. For the last $5 \mathrm{~h}$ of dialysis, the $\mathrm{pH}$ was adjusted to 9 (aq. ammonia) for elimination of N-protonation. Freeze-drying and post-drying (IR unit) gave $1.88 \mathrm{~g}$ (47\%) of water-soluble, solid polyaspartamide 6 .

${ }^{1} \mathrm{H}$ NMR, $\delta$ /ppm: 1.8, $20 \mathrm{H}\left(20 \mathrm{H} ; \mathrm{CH}_{2} \mathrm{CH}_{2} \mathrm{CH}_{2}\right) . ; 2.2,57 \mathrm{H}\left(54 \mathrm{H} ; \mathrm{CH}_{3}\right) ; 3.2,19.5 \mathrm{H}(20 \mathrm{H}$; $\mathrm{CONHCH}_{2}$ ).

To the carrier so obtained, $1.964 \mathrm{~g}(1.0 \mathrm{mmol})$ dissolved in $20 \mathrm{~mL}$ of water, was added $\mathrm{K}_{2} \mathrm{PtCl}_{4}, 0.50 \mathrm{~g}(1.2 \mathrm{mmol})$. Upon dissolution, the $\mathrm{N}_{2}$-saturated solution, protected from light (to prevent metal reduction to $\mathrm{Pt}^{\mathrm{o}}$ ), was stirred for 1 day at room temperature.

During this period the $\mathrm{pH}$ dropped to $7-8$. The reddish-brown solution was further stirred with light protection for $40 \mathrm{~h}$ at $45^{\circ} \mathrm{C}$, while the $\mathrm{pH}$ was maintained at 5-6 (strictly 5-5.5 for the last $0.5 \mathrm{~h}$ ). The routinely filtered solution was freeze-dried, which gave $1.42 \mathrm{~g}$ $(63 \%)$ of $6 \mathrm{Pt}$ as a brownish, water-soluble solid. Anal. calcd. for $\left(\mathrm{C}_{88} \mathrm{H}_{168} \mathrm{Cl}_{2} \mathrm{~N}_{30} \mathrm{O}_{21} \mathrm{Pt}\right)_{\mathrm{n}}$ $(2248.4)_{\mathrm{n}}$ : Pt, 8.7\%. Found: Pt, 8.3\%.

Conjugate 7Pt. The polymer was taken from a previous project [67]. Anal. calcd. for $\left(\mathrm{C}_{91} \mathrm{H}_{174} \mathrm{Cl}_{2} \mathrm{~N}_{30} \mathrm{O}_{23} \mathrm{Pt}\right)_{\mathrm{n}}(2322.6)_{\mathrm{n}}$ : Pt, 8.4\%. Found: Pt, 8.9\%.

Conjugate 8Pt. Carrier synthesis proceeded as described for carrier 6, except that 1,3diaminopropane was replaced by the same molar quantity of diethylenetriamine. Carrier platination as described for $6 \mathrm{Pt}$ afforded conjugate 8Pt in 58\% yield. Anal. calcd. for $\left(\mathrm{C}_{89} \mathrm{H}_{168} \mathrm{Cl}_{2} \mathrm{~N}_{31} \mathrm{O}_{20} \mathrm{Pt}\right)_{\mathrm{n}}(2259.5)_{\mathrm{n}}$ : Pt, 8.64\%. Found: Pt, 8.0\%.

\section{Summary and Conclusions}

Synthetic efforts in the fields of linear and water-soluble, macromolecular aspartamides and amidoamines featuring pairs of carboxyl side groups have provided five carrier polymers designed for conjugation with platinum through dicarboxylatometal chelation. The macromolecular, water-soluble conjugates obtained by treatment of these carriers with DACH-Pt $\left(\mathrm{NO}_{2}\right)_{2}$ (trans-1,2-diaminocyclohexanediaquaplatinum(II) dinitrate) have been screened in vitro for cytotoxicity against the HeLa human cervical adenocarcinoma and three additional human cancer cell lines. The highly promising, although still 
preparatory test results, expressed in terms of $\mathrm{IC}_{50}$ values, reveal cytotoxic activities equal to, or exceeding (by a factor of 100 in tests against the HeLa line) those of the cisplatin standard. Most remarkably, activities determined for the five conjugates as a group against the HeLa line on average are more than 1,000-fold higher than observed for a group of three platinum conjugates, included for comparison, in which the metal, rather than dicarboxylato-chelated, is polymer-conjugated simply by coordination involving carrier-attached amine or diamine ligands. Obtained on a limited number of samples, however, these preliminary findings need confirmation and expansion in more extended screens of increased sample size. Forthcoming investigations will focus on this requirement.

\section{References}

1. B. Rosenberg, L. van Camp, T. Krigas, Nature 205, 698 (1965). See also: Cancer Chemother. Rep. Part I. 59, 589 (1975)

2. K.R. Harrap, in Cancer Chemotherapy, vol. 1, Chap. 7, ed. by F.M. Muggia (Martinus Nijhoff, MA, 1983)

3. J.C. Dabrowiak, W.T. Bradner, Progr. Med. Chem. vol 24, ed. by G.P. Ellis, G.B. West (Elsevier Science Publ., 1987)

4. W.R. Waud, in Cancer Chemotherapeutic Agents, ed. by W.O. Foye (Am. Chem. Soc, Washington DC, 1995), p. 121

5. M.J. Cleare, Coord. Chem. Rev. 12, 349 (1974). See also: Dev. Pharmacol. 3, 59 (1983)

6. M.J. Cleare, J.D. Hoeschele, Platinum Metal. Rev. 6, 17 (1979). See also: Bioionorg. Chem. 2, 187 (1973)

7. Cisplatin : Current Status and New Developments, ed. by A. Prestayko, S. Crooke, S. Carter (Academic Press, 1980)

8. N. Farrell, in Transition Metal Complexes as Drugs and Chemotherapeutic Agents (Kluwer Academic, Dordrecht, 1989), p. 67. See also: in Platinum and Other Metal Coordination Compounds in Cancer Chemotherapy, ed. by S.B. Howell (Plenum Press, 1991), p. 81

9. P.C. Hydes, M.J.H. Russell, Cancer Metastasis Rev. 7, 67 (1988) 
10. S.J. Lippard, Pure Appl. Chem. 59, 731 (1987)

11. J. Reedijk, A.M.J. Fichtinger-Schepman, A.T. van Oosterom, P. van de Putte, Struct. Bonding 67, 53 (1987). See also: Pure Appl. Chem. 59, 181 (1987); Chem. Rev. 99, 2499 (1999); Chem. Commun. 801 (1996)

12. E.W. Neuse, C.W.N. Mbonyana, in Inorganic and Metal-containing Polymeric Materials, ed. by J.E. Sheats et al. (Plenum Press, New York, 1990), p. 139

13. M.J. McKeage, L.R. Kelland, in Molecular Aspects of Drug-DNA Interactions, ed. by S. Neidle, M.J. Waring (MacMillan, New York, 1992), p. 1

14. L.R. Kelland, Drugs Future 18, 551 (1993). See also: Crit. Revs. Oncol./Hematol. 15, 191 (1993)

15. C.M. Giandomenico et al., in Platinum and Other Metal Coordination Compounds in Cancer Chemotherapy, ed. by S.B. Howell (Plenum Press, New York, 1991), p. 93

16. T.W. Hambley, Coord. Chem. Rev. 166, 181 (1997)

17. E.W. Neuse, Polym. Adv. Technol. 9, 786 (1998)

18. I. Kostova, Rec. Patents on Anti-Cancer Drug Discov. 1, 1 (2006)

19. D.W. Siegmann-Louda, C.E. Carraher, in Macromolecules Containing Metal and Metal-like Elements, Vol. 3, Biomedical Applications, Chap. 7, ed. by A.S. Abd-ElAziz, C.E. Carraher, C.U. Pittman, J.E. Sheats, M. Zeldin (Wiley, 2004)

20. E.W. Neuse, S. Afr. J. Sci. 95, 509 (1999)

21. H. Ringsdorf, J. Polym. Sci. Polym. Symp. 51, 135 (1975)

22. H. Maeda, Adv. Drug Deliv. Rev. 6, 181 (1991), and earlier reports from this author

23. R. Duncan, J. Kopeček, Adv. Polym. Sci. 57, 51 (1984); ibid 122, 55 (1995)

24. H.J.-P. Ryser, W.C. Shen, in Targeting of Drugs with Synthetic Systems, ed. by G. Gregoriadis et al. (Plenum Press, 1986), p. 103 
25. C.J.T. Feijen, in Drug Carrier Systems, ed. by F.H.D. Roerdink, A.M. Kroon (Wiley, 1989), p. 57

26. S.E. Matthews, C.W. Pouton, M.D. Threadgill, Adv. Drug Deliv. Rev. 18, 219 (1996)

27. H. Maeda, J. Wu, T. Sawa, Y. Matsumura, K. Hori, J. Control Release. 65, 271 (2000)

28. T. Minko, P. Kopečková, J. Kopeček, Macromol. Symp. 172, 35 (2001)

29. R. Duncan, Nat. Rev./Drug Discov. 2, 247 (2003)

30. R.J. Christie, D.W. Grainger, Adv. Drug Deliv. Rev. 55, 421 (2003)

31. R. Duncan, M.J. Vicent, F. Greco, R.I. Nicholson, Endocr. Relat. Cancer 12, S189 (2005)

32. A. Nori, J. Kopeček, Adv. Drug Deliv. Rev. 57, 609 (2005)

33. O. Hovorka, T. Etrych, V. Šubr, J. Strohalm, K. Ulbrich, B. Rihová, J. Drug Target. 14, $391(2006)$

34. E.W. Neuse, G. Caldwell, J. Inorg. Organometal. Polym. 7, 163 (1997)

35. E.W. Neuse, B.B. Patel, C.W.N. Mbonyana, J. Inorg. Organometal. Polym. 1, 147 (1991)

36. G. Caldwell, E.W. Neuse, C.E.J. van Rensburg, J. Inorg. Organometal Polym. 7, 217 (1997)

37. C.L. Luthy et al., Proc. Int. Symp. Control Rel. Bioact. Mater. 25, 132 (1998)

38. E. Gianasi, M. Wasil, E.G. Evagorou, A. Keddle, G. Wilson, R. Duncan, Eur. J. Cancer 35, 994 (1999)

39. C.W.N. Mbonyana, E.W. Neuse, A.G. Perlwitz, Appl. Organometal. Chem. 7, 279 (1993)

40. E.W. Neuse, A.G. Perlwitz, G. Caldwell, J. Inorg. Organometal. Polym. 5, 195 (1995) 
41. G. Caldwell, E.W. Neuse, A.G. Perlwitz, J. Inorg. Organometal. Polym. 7, 111 (1997)

42. G. Caldwell, E.W. Neuse, C.E.J. van Rensburg, Appl. Organomet. Chem. 13, 189 (1999)

43. M.T. Johnson, E.W. Neuse, C.E.J. van Rensburg, E. Kreft, J. Inorg. Organometal. Polym. 13, 55 (2003)

44. E.W. Neuse, Macromol. Symp. 80, 111 (1994)

45. E.W. Neuse, Chem. Perspect. 1, 69 (2000)

46. B. Schechter, A. Neumann, M. Wilchek, R. Arnon, J. Control Release 10, 75 (1989)

47. D. Avichezer, B. Schechter, R. Arnon, React. Funct. Polym. 36, 59 (1998)

48. B. Schechter, R. Arnon, Y.E. Freedman, L. Chen, M. Wilchek, J. Drug Target. 4, 171 (1996). See also: React. Polym. 25, 167 (1995)

49. Y. Ohya, T. Masunaga, T. Baba, T. Ouchi, Pure Appl. Chem. A33, 1005 (1996). See also: J. Biomater. Sci. Polymer Edn. 7, 1085 (1996)

50. M. Nakashima et al., Biol. Pharm. Bull. 22, 756 (1999)

51. Y. Ohya, S. Shirakawa, M. Matsumoto, T. Ouchi, Polym. Adv. Technol. 11, 635 (2000)

52. Y. Ohya, K. Nagatomi, T. Ouchi, Macromol. Biosci. 1, 355 (2001)

53. Y. Ohya, H. Oue, K. Nagatomi, T. Ouchi, Biomacromolecules 2, 927 (2001)

54. P. Neri, G. Antoni, F. Benvenuti, F. Cocola, G. Gazzai, J. Med. Chem. 16, 893 (1973)

55. P. Neri, G. Antoni, Macromol. Synt. 8, 25 (1982)

56. J. Kalal, J. Drobnı̌k, J. Kopeček, J. Exner, Brit. Polym. J. 10, 111 (1978)

57. J. Drobnǐk, V. Saudek, J. Vlasák, J Kálal, J. Polym. Sci. Polym. Symp. 66, 59, 65 (1979) 
58. J. Pytela, V. Saudek, J. Drobnǐk, F. Rypáček, J. Control Release 10, 17 (1989). See also: Ann. NY Acad. Sci. 446, 258 (1985)

59. F. Danusso, P. Ferruti, Polymer 11, 88 (1970)

60. P. Ferruti, M.A. Marchisio, R. Duncan, Macromol. Rapid Commun. 23, 332 (2002), and numerous preceding papers from that group

61. G. Caldwell, E.W. Neuse, S. Afr. J. Chem. 45, 93 (1992)

62. G. Caldwell, E.W. Neuse, A. Stephanou, J. Appl. Polym. Sci. 50, 393 (1993)

63. M.L. de Machado, E.W. Neuse, A.G. Perlwitz, S. Schmitt, Polym. Adv. Technol. 1, $275(1990)$

64. M.T. Johnson, L.L. Komane, D.D. N'Da, E.W. Neuse, J. Appl. Polym. Sci. 96, 10 (2005)

65. C.E.J. van Rensburg, A.M. van Staaden, R. Anderson, Cancer Res. 53, 318 (1993)

66. J.D. Hoeschele, N. Farrell, W.R. Turner, C.D. Rithner, Inorg. Chem. 27, 4106 (1988)

67. B. Schechter, G. Caldwell, M.G. Meirim, E.W. Neuse, Appl. Organometal. Chem. 14, $701(2000)$ 